\title{
INTENSIVE PERIOPERATIVE GLUCOSE CONTROL DOES NOT IMPROVE OUTCOMES OF PATIENTS SUBMITTED TO OPEN-HEART SURGERY: A RANDOMIZED CONTROLLED TRIAL
}

\author{
Raquel Pei Chen Chan, Filomena Regina Barbosa Gomes Galas, Ludhmila \\ Abrahão Hajjar, Carmen Narvaes Bello, Marilde Albuquerque Piccioni, José \\ Otávio Costa Auler Jr.
}

doi: 10.1590/S1807-59322009000100010

Chan RPC, Galas FRBG, Hajjar LA, Bello CN, Piccioni MA, Auler Jr JOC. Intensive perioperative glucose control does not improve outcomes of patients submitted to open-heart surgery: a randomized controlled trial. Clinics. 2009;64(1):51-60.

BACKGROUND: The objective of this study was to investigate the relationship between different target levels of glucose and the clinical outcomes of patients undergoing cardiac surgery with cardiopulmonary bypass.

METHODS: We designed a prospective study in a university hospital where 109 consecutive patients were enrolled during a six-month period. All patients were scheduled for open-heart surgery requiring cardiopulmonary bypass. Patients were randomly allocated into two groups. One group consisted of 55 patients and had a target glucose level of 80-130 mg/dl, while the other contained 54 patients and had a target glucose level of 160-200 mg/dl. These parameters were controlled during surgery and for 36 hours after surgery in the intensive care unit. Primary outcomes were clinical outcomes, including time of mechanical ventilation, length of stay in the intensive care unit, infection, hypoglycemia, renal or neurological dysfunction, blood transfusion and length of stay in the hospital. The secondary outcome was a combined end-point (mortality at 30 days, infection or length of stay in the intensive care unit of more than 3 days). A p-value of $<0.05$ was considered significant.

RESULTS: The anthropometric and clinical characteristics of the patients from each group were similar, except for weight and body mass index. The mean glucose level during the protocol period was $126.69 \mathrm{mg} / \mathrm{dl}$ in the treated group and $168.21 \mathrm{mg} / \mathrm{dl}$ in the control group $(\mathrm{p}<0.0016)$. There were no differences between groups regarding clinical outcomes, including the duration of mechanical ventilation, length of stay in the intensive care unit, blood transfusion, postoperative infection, hypoglycemic event, neurological dysfunction or 30-day mortality ( $\mathrm{p}>0.05$ ).

CONCLUSIONS: In 109 patients undergoing cardiac surgery with cardiopulmonary bypass, both protocols of glycemic control in an intraoperative setting and in the intensive care unit were found to be safe, easily achieved and not to differentially affect clinical outcomes.

KEYWORDS: Cardiac surgery; Glucose control; Open-heart surgery.

\section{INTRODUCTION}

An emerging body of medical literature has described

Department of Anesthesia and Surgical Intensive Care Unit, Instituto do Coração (InCor), Hospital das Clínicas, Faculdade de Medicina, Universidade de São Paulo.

Email: auler@hcnet.usp.br / prodcient_anest@incor.usp.br

Tel.: 55113069.5232

Fax: 55113069.5367

Trial registration - NCT00370643

Received for publication on May 26, 2008

Accepted for publication on October 1, 2008 the adverse consequences of hyperglycemia in a variety of different clinical contexts. Hyperglycemia occurs commonly among patients with acute neurological disease, ${ }^{1-5}$ ischemic heart disease ${ }^{6-10}$ and a range of surgical and trauma events. ${ }^{11-13}$ Its development has been attributed to numerous stress, counter regulatory, and iatrogenic factors. ${ }^{14} \mathrm{~A}$ review ${ }^{15}$ of 1,826 patients admitted to adult medical-surgical intensive care units (ICU) demonstrated a strong association between increasing glucose levels during ICU admission and risk of mortality. The lowest hospital mortality occurred among patients with mean glucose levels of 80 to $100 \mathrm{mg} / \mathrm{dl}$ during 
their ICU stay; the rate of hospital mortality increased dramatically for every $20 \mathrm{mg} / \mathrm{dl}$ increment above this normal level.

There are relatively few studies in the literature reporting improved outcomes with control of blood glucose in the acute setting. ${ }^{16-19}$ A landmark randomized, controlled study ${ }^{18}$ performed in a surgical ICU included 1,548 patients receiving mechanical ventilation, $63 \%$ of whom had undergone cardiac surgery. The study demonstrated a significant reduction in ICU mortality, reduced from $8.0 \%$ to $4.6 \%$, and impressive reductions in numerous organ system dysfunctions with an intensive regimen that targeted euglycemia. In addition to saving lives, intensive insulin therapy largely prevented several critical illnessassociated complications. The incidences of critical illness polyneuropathy, bloodstream infections, acute renal failure and anemia were reduced. ${ }^{18}$

In 2006, after the first surgical study, a second large, prospective, randomized controlled trial by the Leuven group ${ }^{20}$ was published on the effects of tight glycemic control in adult patients admitted to the medical ICU. In-hospital mortality of the intention-to-treat population of 1200 medical ICU patients was reduced, although not significantly. The lack of significance was not surprising, as the study was not statistically powered for this endpoint. In the target group of long-stay patients, maintaining normoglycemia significantly reduced in-hospital mortality from $52.5 \%$ to $43.0 \%(P=0.009)$. Morbidity was significantly reduced in the intention-to-treat group when they received intensive insulin therapy, where this reduction was even more striking in the target group. Patients were less dependent on prolonged mechanical ventilation and were discharged earlier from the ICU and hospital. In the subgroup of long-stay ICU patients, intensive insulin therapy also prevented newly acquired kidney injury, reduced the incidence of hyperinflammation and reduced the incidence of critical illness polyneuropathy or myopathy.

Questions have been raised about the efficacy of this technique in general and in specific subgroups. Additional issues include the safety of intensive insulin therapy with regard to the potential harm of brief hypoglycemic episodes and of high-dose insulin administration..$^{21-24}$ In a recent study, the prospective, randomized, multicenter VISEP (Efficacy of Volume Substitution and Insulin Therapy in Severe Sepsis) trial was designed as a four-arm study to assess the choice of fluid resuscitation and the efficacy and safety of intensive insulin therapy in patients with severe sepsis and septic shock. Mortality and organ dysfunction were utilized as outcome parameters. ${ }^{25}$ The insulin arm of the study was stopped prematurely because the rate of hypoglycemia in the intensive treatment group was considered unacceptably high (12.1\%).
Data provided by recently completed trials reveal that we should regard tight glucose control during cardiac surgery as experimental and confine its use to clinical trials. ${ }^{23,25}$ In light of this suggestion, we aimed to investigate whether different targets of intraoperative and postoperative glucose (80-130 $\mathrm{mg} / \mathrm{dl}, 4.4-7.2 \mathrm{mEq} / \mathrm{l}$ or $160-200 \mathrm{mg} / \mathrm{dl}, 8.8-11.1 \mathrm{mEq} / \mathrm{l})$ could affect postoperative clinical outcomes after cardiac surgery with cardiopulmonary bypass.

\section{METHODS}

\section{Patient Selection}

The study was a prospective, randomized, controlled trial performed in the operating room and in the cardiac surgical intensive care unit (ICU). The protocol of glycemic control was modified from data provided in the literature ${ }^{18}$ and was approved by the Institution Ethics and Scientific Committee. Written informed consent was obtained from patients a day before the surgery.

Over a period of 12 months, 300 patients were submitted to cardiac surgery at InCor - Heart Institute. Of these 300 patients, 191 were excluded; 39 patients due to renal failure, 116 patients because they required inotropic support and 36 patients because of emergency surgery. One-hundrednine patients scheduled for open-heart surgery requiring cardiopulmonary bypass (CBP) were enrolled. The patients were randomized into two groups through a lottery system. The first group was named the "treated group" (intensive protocol), with a target glucose level between $80-130 \mathrm{mg} / \mathrm{dl}$. The second group was the "control group" (less intensive), with a target glucose level between 160-200 mg/dl. In the latter case, infusion of insulin was initiated only if blood glucose levels exceeded $200 \mathrm{mg} / \mathrm{dl}$. Continuous intravenous regular insulin was used to control glucose levels (regular insulin, U100, Biobrás, Montes Claros, Brazil) when protocol criteria were met, using an infusion device.

The study group included adults from both genders who were older than 21 years of age and who were undergoing open-heart cardiac surgery with CPB. The exclusion criteria included: (1) renal failure (creatinine $>1.5 \mathrm{~g} / \mathrm{dl}$ ), (2) neurological dysfunction (diagnosis from medical records), (3) chronic pulmonary obstructive disease (CPOD), (4) current use of any type of antibiotic, (5) current use of inotropic support, (6) emergency and urgent surgeries and (7) reoperations.

\section{Protocol for glycemic control}

At the beginning of the study, all patients were kept in intraoperative rooms and were started on intravenous 
glucose $(8-12 \mathrm{~g} / \mathrm{hr})$, which was maintained for the first 24 hours after arrival in the ICU. After 24 hours, patients started a standardized feeding schedule, intended to deliver 20-30 nonprotein calories $\cdot \mathrm{kg}^{-1} \cdot 24 \mathrm{hrs}^{-1}$ with a balanced composition (0.13-0.26 g nitrogen $\cdot \mathrm{kg}^{-1} \cdot 24 \mathrm{hrs}^{-1}$ and $20-40 \%$ of nonprotein calories as lipids) of enteral feeding. All of the patients were able to receive enteral feeding after surgery. Parenteral nutrition was not prescribed for any patients in the study. Patients were randomly assigned to either intensive or conventional insulin treatment. Adjustment of the insulin dose was based on the measurements of whole blood glucose in undiluted arterial blood every one to four hours, using a glucose analyzer (ABL700, Radiometer Medical A/S, Copenhagen, Denmark). The dose was adjusted by the intensive care nurses according to a titration algorithm (Leuven modified), as stipulated below. These insulin doses were approved by a study physician not involved in the clinical care of the patients. The nurses were advised to consider the titration algorithm as a directive rather than strict numerical instructions.

Insulin was given exclusively by continuous intravenous infusion through a central venous catheter using an infusion device (B. Braun, Melsungen, Germany). The standard concentration was 100 IU of Actrapid HM (Novo Nordisk, Copenhagen, Denmark) in $100 \mathrm{~mL}$ of $0.9 \% \mathrm{NaCl}$. Prepared solutions, which were stable for up to $12 \mathrm{hrs}$ when kept at $<25^{\circ} \mathrm{C}$, were not to be used beyond that time. Whole blood glucose levels were measured on site in undiluted arterial blood. Undiluted samples were obtained by removing at least four times the flush volume in the arterial catheter between the sampling point and the arterial puncture site before the actual sample was taken. During the intraoperative period and during the first 24 hours after admission to the ICU, measurement of blood glucose was advised every one to two hours until the targeted level of blood glucose was achieved. Thereafter, blood glucose was measured every four hours, unless dramatic decreases or increases in the blood glucose level occurred. In these cases, hourly control was performed after each dose adjustment.

Adequate administration of the prescribed nutrients was emphasized. Intravenous glucose-containing solutions were administered by an infusion pump to avoid fluctuation of blood glucose levels and frequent adjustment of the insulin dose. At the time of planned interruptions of feeding, the insulin dose was proportionately reduced to avoid hypoglycemia. Hence, in a patient receiving total enteral nutrition, insulin was virtually stopped during the twice daily, two-hour interruptions of tube feeding. In some patients, however, including those with diabetes and those requiring insulin before ICU admission, a low maintenance dose was needed during that time. At the time of patient transportation to an investigation or to the operating room for surgery, all intravenous and enteral administration of feeding was halted, and insulin infusion was temporarily discontinued. The blood glucose level was measured to ensure that it was adequate before transport. Whenever a patient was extubated and allowed to initiate a limited intake of oral foods, the intravenous or tube feeding was usually reduced to allow the patient's appetite to return. The insulin dose was proportionately reduced and often temporarily discontinued.

\section{Initiation of Insulin Infusion and Initial Stabilization of Blood Glucose Level}

When the blood glucose level exceeded $130 \mathrm{mg} / \mathrm{dl}$, insulin was started at $2 \mathrm{IU} / \mathrm{hr}$ (4 IU/hr if the first blood glucose level exceeded $220 \mathrm{mg} / \mathrm{dl}$ ). When the next blood glucose reading was $>150 \mathrm{mg} / \mathrm{dL}$, the insulin dose was increased by $1-2 \mathrm{IU} / \mathrm{hr}$. When the subsequent blood glucose level was $110-140 \mathrm{mg} / \mathrm{dl}$, insulin was increased by 0.5 to $1 \mathrm{IU} / \mathrm{hr}$. When blood glucose approached $80-110 \mathrm{mg} / \mathrm{dl}$, insulin was adjusted by 0.1 to 0.5 IU/hr. When the blood glucose level was $80-110 \mathrm{mg} / \mathrm{dl}$, the insulin dose was unaltered.

\section{Dose Adjustments After Initial Stabilization}

Dose adjustments were always proportionate to the observed change in blood glucose. When blood glucose decreased by $>50 \%$, the dose of insulin was reduced to half, and the blood glucose level was checked within the next hour. When blood glucose was $60-80 \mathrm{mg} / \mathrm{dl}$, insulin was reduced depending on the previous blood glucose level, and the blood glucose level was checked again within the next hour. When blood glucose was 40-60 mg/dl, insulin infusion was stopped, an adequate baseline glucose intake was ensured, and the blood glucose level was checked within the next hour. When the blood glucose was $<40 \mathrm{mg} / \mathrm{dl}$, insulin infusion was stopped, an adequate baseline glucose intake was ensured, glucose was administered via $10 \mathrm{~g}$ intravenous boluses, and the blood glucose level was checked within the next hour. When blood glucose started to decrease within the normal range in a stable patient, recovery of insulin sensitivity was assumed, and the insulin dose was reduced by $20 \%$. Additional blood glucose controls were advised whenever changes in body temperature or infection occurred.

\section{CONVENTIONAL INSULIN THERAPY}

\section{Initiation and Dose Adjustment of Insulin Infusion}

As soon as the blood glucose level exceeded $200 \mathrm{mg} /$ $\mathrm{dl}$, insulin infusion was initiated at an initial dose of $1 \mathrm{IU} /$ 
hr. When a control blood glucose level was $>200 \mathrm{mg} / \mathrm{dl}$, the insulin dose was increased by increments of $1 \mathrm{IU} / \mathrm{hr}$. Once the blood glucose level was between 180 and $200 \mathrm{mg} / \mathrm{dl}$, the insulin dose was maintained constant. When the blood glucose level decreased to $<180 \mathrm{mg} / \mathrm{dl}$, insulin infusion was decreased until the blood glucose level was between 180 and $200 \mathrm{mg} / \mathrm{dl}$. The insulin dose was further reduced and eventually stopped completely when blood glucose levels decreased further. Insulin infusion was returned when blood glucose exceeded $200 \mathrm{mg} / \mathrm{dl}$.

\section{Intraoperative and ICU Management}

Surgical and anesthesia management did not differ from routine care. All patients were given oral midazolam at $0.5 \mathrm{mg} / \mathrm{kg}$ as premedication (maximum $15 \mathrm{mg}$ ), general anesthesia with propofol (dose depending on hemodynamics), $0.5-1 \mu \mathrm{g} / \mathrm{kg}$ sufentanil, $0.5 \mathrm{mg} / \mathrm{kg}$ atracurium and isoflurane titrated to a hemodynamic effect. In accordance with the routine protocol, $20 \mathrm{mg} /$ $\mathrm{kg}$ methyilprednisolone (maximum $1 \mathrm{~g}$ ) was given after induction of anesthesia. The use of inotropic support was dependent on patients' needs. The threshold for a red blood cell blood transfusion was a hematocrit of less than $30 \%$. Second generation cephalosporin was given as prophylaxis before sternotomy and after cardiopulmonary bypass (CPB), per hospital protocol. Antifibrinolytic therapy with aminocaproic acid was used as needed according to institutional protocol. Lactated Ringer's solution was used to increase the volume. Cardiopulmonary bypass temperature depended on the type of surgery and varied from profound to mild hypothermia. Hematocrit, before and after $\mathrm{CPB}$, was set above $30 \%$ and, during CPB, between $23-25 \%$.

All subjects who met criteria for the study started glucose control after arrival in the operating room, immediately after standard monitoring, anesthesia induction and tracheal intubation. They were subsequently examined every hour until the end of the operation. Then, on admittance to the ICU, hourly glucose control resumed until glucose levels stabilized, and at that time, glucose control was performed every 2 hours for 36 hours. The glucose level was determined in blood samples and measured by a glucose meter (Accu Check Advantage, Roche, Manheim, Germany), which proved to be precise and exact when handled by trained personnel. $^{26}$

\section{Analyzed Variables}

Patients' anthropometric and clinical characteristics were collected, and pre-operative cardiac and risk evaluations were applied. The type of surgery performed, the duration of the surgery and the elapsed time of CPB were also registered.

Primary outcomes were clinical outcomes, which included the duration of mechanical ventilation from the operation room until extubation in the intensive care unit (ICU), the length of stay in the ICU, occurrence of infection (diagnosis of pneumonia, urinary tract infection, sepsis, septic shock, wound infection, blood stream infection, catheter infection), occurrence of hypoglycemia (glucose level $\leq 50 \mathrm{mg} / \mathrm{dl}$ ), renal dysfunction (characterized as an increase in the level of creatinine higher than $50 \%$ of the baseline value), neurological dysfunction (diagnosis by hospital neurologist who was blinded to the protocol), red blood cell transfusion during the first 30 days after surgery, the length of stay in the hospital and mortality by 30 days after surgery. We contacted patients by telephone and used a standardized telephone survey at 30 days after surgery to assess outcomes that occurred after discharge. The physicians and nurse who obtained the clinical data were blinded to the randomization of the group.

\section{Statistical analysis}

The student T-test was used to assess differences between the two groups regarding age, weight, height and corporeal mass index. The Fisher $\chi^{2}$ exact test was utilized, when appropriate, to compare the treated and control groups regarding sex, physical status, incidence of renal failure, presence of infection, use of antifibrinolytics, neurological dysfunction and mortality. The Mann-Whitney test was employed to assess differences concerning cardiac operative risk evaluations, preoperative laboratory data, duration of surgery, CPB time, duration of intubation, length of stay in the hospital and ICU, blood transfusion and amount of antifibrinolytic used. The ANOVA test was used to compare data from both groups regarding the glucose levels obtained during surgery and in the ICU.

\section{RESULTS}

The results of this study are presented in tables and figures with mean age and standard deviation or median when suitable. Eleven patients from both groups were withdrawn from the study; five of them required a second operation due to bleeding, three had hemodynamic instability that required an aortic balloon, and three had serious ventricular tachycardia that required electric shock. Ninetyeight patients were enrolled in this study, including fifty-one in the control group and forty-seven in the treated group.

Thirty-two patients were diagnosed with diabetes mellitus and sixty-six were diagnosed as non-diabetic. Table 1 shows the anthropometric characteristics of the patients in 
both groups. The control and treated groups were comparable with respect to age, gender and height, but the treated group was slimmer and had a lower body mass index (BMI).

There were some slight differences in the treated and control groups related to the classification of physical status by the ASA (American Society of Anesthesiologists). In the control arm of the study, $86.3 \%$ of the patients were P4 and, in the treated arm, $70.2 \%$ of the patients were P4. After applying the risk evaluation for cardiac surgical patients from EuroSCORE ${ }^{27}$ and from Canadian research, ${ }^{28}$ no differences were found between the two groups. The same results were obtained when the risk evaluation from Bernstein and Parsonnet ${ }^{29}$ was applied (Table 1). Glucose level, total cholesterol, hematocrit and triglycerides before surgery were similar between the two studied groups. Although similar, clearance of creatinine in both groups was mildly lower than the normal range (Table 1). The type of surgical procedure is described on Table 2.

Neither the type of surgery, duration of surgery or the CPB time was different between the two study groups (Tables 3 ). The use of antifibrinolytics until extubation in the ICU also showed no statistically significant differences between the two groups; the duration of use ranged from 10 hours to 15 minutes in the control group and 10 hours to 55 minutes in the treated group. In relation to the length of stay in the ICU, both groups were comparable, with 5.9 days for the control group and 4.1 days for the treated group $(\mathrm{p}=0.481)$.

Table 1 - Anthropometric characteristics, preoperative risk and preoperative laboratory data

\begin{tabular}{lcc}
\hline & $\begin{array}{c}\text { Control Group } \\
(\mathrm{n}=55)\end{array}$ & $\begin{array}{c}\text { Treated Group } \\
(\mathrm{n}=54)\end{array}$ \\
\hline Male (\%) & 56.9 & 43.1 \\
Age (years), mean (SD) & $58( \pm 12)$ & $57( \pm 12)$ \\
Weight (kg), mean (SD) & $68.7( \pm 12.9)$ & $63.3( \pm 11.2)$ \\
Height (cm), mean (SD) & $162.5( \pm 8.4)$ & $162.1( \pm 8.3)$ \\
BMI, mean (SD) & $26( \pm 4.9)$ & $24( \pm 3.4)$ \\
ASA (physical status) - P4 (\%) & 86.3 & 70.2 \\
EuroSCORE®, mean( SD) & $3.5( \pm 2.1)$ & $3.2( \pm 2.2)$ \\
Canadian, mean(SD) & $3.0( \pm 2.4)$ & $3.0( \pm 2.3)$ \\
Parsonnet, mean(SD) & $11.1( \pm 6.1)$ & $11.3( \pm 7.0)$ \\
Glucose preop & $138.4( \pm 74.6)$ & $113.4( \pm 42.5)$ \\
Cholesterol & $220.8( \pm 135.7)$ & $189.1( \pm 42.3)$ \\
Triglycerides & $135.5( \pm 62.4)$ & $122.7( \pm 63.8)$ \\
Creatinine & $76.3( \pm 18.9)$ & $72.1( \pm 17.7)$ \\
Hematocrit - \% & $40.9( \pm 3.9)$ & $41.7( \pm 4.5)$ \\
\hline
\end{tabular}

$* \mathrm{P} \leq 0,05$ value statistically significant

Obs: Glucose preop = glucose level preoperative, $\mathrm{mg} / \mathrm{dl}$; Cholesterol = total cholesterol, $\mathrm{mg} / \mathrm{dl}$; Triglycerides $=\mathrm{mg} / \mathrm{dl} ;$ Creatinine $=$ creatinine clearance $\mathrm{ml} / \mathrm{min} ; \mathrm{P} \leq 0,05$ value statistically significant
Table 2 - Diagnostic categories

\begin{tabular}{lcc}
\hline Procedures & $\begin{array}{c}\text { Control Group } \\
(\mathrm{n}=55)\end{array}$ & $\begin{array}{c}\text { Treated Group } \\
(\mathrm{n}=54)\end{array}$ \\
\hline $\begin{array}{l}\text { Coronary artery bypass graft } \\
\text { (CABG) }\end{array}$ & 19 & 16 \\
$\begin{array}{l}\text { Combined CABG and mitral valve } \\
\text { plastic or replacement }\end{array}$ & 0 & 2 \\
$\begin{array}{l}\text { Combined CABG and aortic v. } \\
\text { replacement }\end{array}$ & 4 & 4 \\
$\begin{array}{l}\text { Combined CABG and correction of } \\
\text { ventricular aneurysm }\end{array}$ & 1 & 5 \\
Mitral v. plastic or replacement & 7 & 13 \\
$\begin{array}{l}\text { Aortic v. plastic or replacement } \\
\text { Combined mitral v. replacement and } \\
\text { tricuspid exploration }\end{array}$ & 11 & 6 \\
Combined mitral v. plastic and aortic & 4 & 5 \\
v. replacement & & 3 \\
$\begin{array}{l}\text { Ascending aortic aneurysm cor- } \\
\text { rection }\end{array}$ & 2 & 0 \\
Atrial septal defect closure & 3 & 0 \\
Complex* & 1 & 0 \\
\hline
\end{tabular}

Obs: Complex*: combined ascending aortic aneurysm correction + aortic valve replacement $+\mathrm{CABG}$

Table 3 - Operative data

\begin{tabular}{lccc}
\hline & $\begin{array}{c}\text { Control Group } \\
(\mathrm{n}=55)\end{array}$ & $\begin{array}{c}\text { Treated Group } \\
(\mathrm{n}=54)\end{array}$ & $\mathrm{P}$ \\
\hline $\begin{array}{l}\text { Length of surgery (min), } \\
\text { mean (SD) }\end{array}$ & $310.4( \pm 111.0)$ & $271.4( \pm 66.2)$ & 0.122 \\
$\begin{array}{l}\text { Length of CPB (min), } \\
\text { mean (SD) }\end{array}$ & $116.3( \pm 54)$ & $97.9( \pm 45.3)$ & 0.060 \\
Antifibrinolytics (\%) & 68.6 & 57.5 & 0.240 \\
\hline
\end{tabular}

$\mathrm{P} \leq 0,05$ value statistically significant

The mean glucose level during the protocol period was $126.69( \pm 10.82) \mathrm{mg} / \mathrm{dl}$ in the treated group and $168.21( \pm$ 28.29 ) in the control group. These results were statistically different (Figure 1).

The intensively treated patients (Table 4) received higher total and daily doses of insulin compared to the control group $(\mathrm{p}<0.05)$.

Clinical outcomes were not different between the two groups. Primary and secondary outcomes were parallel $(p>0.05)$. The duration of intubation from anesthetic induction was also quite similar in both groups $(\mathrm{p}=0.831)$.

Both groups were comparable regarding the use of allogeneic blood. Four units of packed red cells were used in the control group in comparison with 3.5 units in the treated group ( $\mathrm{p}=0.20)$, as shown in Table 5. The rate of hypoglycemia, which was considered to be the ratio of the 


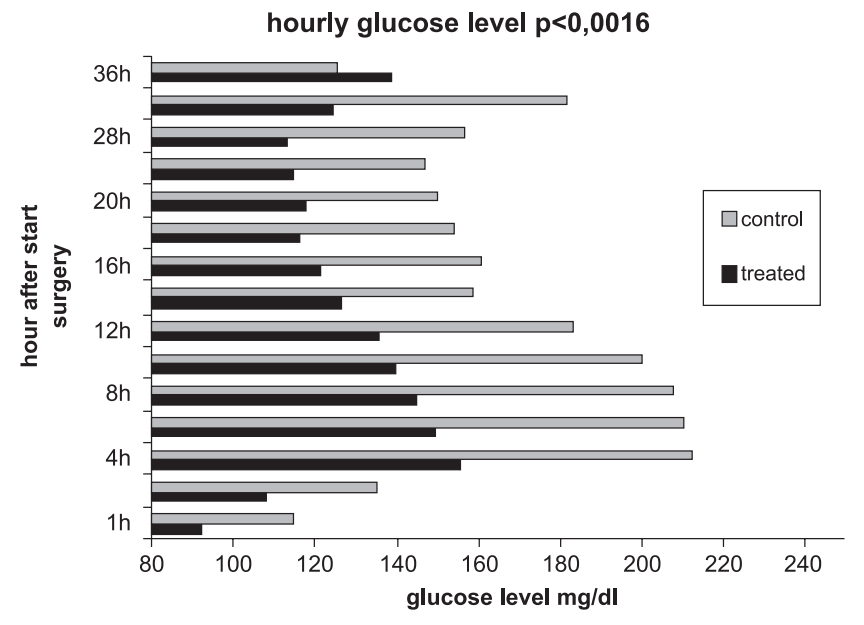

\begin{tabular}{|c|c|c|}
\hline Time of collection & $\begin{array}{c}\text { Control } \\
\text { (standard deviation) }\end{array}$ & $\begin{array}{c}\text { Treated } \\
\text { (standard deviation) }\end{array}$ \\
\hline $1 \mathrm{~h}$ & 18 & 13 \\
\hline $4 \mathrm{~h}$ & 34 & 28 \\
\hline $8 \mathrm{~h}$ & 39 & 31 \\
\hline $12 \mathrm{~h}$ & 26 & 28 \\
\hline $16 \mathrm{~h}$ & 31 & 31 \\
\hline $20 \mathrm{~h}$ & 26 & 25 \\
\hline $28 \mathrm{~h}$ & 22 & 24 \\
\hline $36 \mathrm{~h}$ & 19 & 24 \\
\hline
\end{tabular}

Figure 1 - Glucose levels $(\mathrm{mg} / \mathrm{dL})$ in control and intensively treated groups. Standard deviation is represented below

Table 4 - Total and daily doses of insulin in each group

\begin{tabular}{lccc}
\hline Risk & $\begin{array}{c}\text { Control Group } \\
(\mathrm{n}=55)\end{array}$ & $\begin{array}{c}\text { Treated group } \\
(\mathrm{n}=54)\end{array}$ & $\mathrm{P}$ \\
\hline $\begin{array}{l}\text { Patients who received } \\
\text { insulin, (\%) }\end{array}$ & $49(100)$ & $43(87.7)$ & 0.21 \\
$\begin{array}{l}\text { Daily doses of insulin, } \\
\text { mean (SD) }\end{array}$ & $8( \pm 6)$ & $61( \pm 26)$ & $0.04^{*}$ \\
$\begin{array}{l}\text { Total doses of insulin, } \\
\text { mean (SD) }\end{array}$ & $28( \pm 9)$ & $121( \pm 34)$ & $0.03^{*}$ \\
\hline
\end{tabular}

$* \mathrm{P} \leq 0,05$ value statistically significant

hypoglycemic episodes per number of glucose measurements (2.1\% in the control group and $2.9 \%$ in the intensive group, $\mathrm{p}=0.67$ ), was similar between the groups.

Although $35.3 \%$ of the patients from the control group and $19.2 \%$ of the patients from the treated group had a postoperative infection, this difference did not reach statistical significance $(\mathrm{p}=0.11)$. Table 5 describes the documented infections. Respiratory tract infections were the most common infection, and both groups had the same frequency of this type of infection. There were no cases of septic shock, catheter infection or bloodstream infection. Renal dysfunction occurred in $9.8 \%$ of the patients from the control group and $6.4 \%$ of
Table 5 - Clinical outcomes

\begin{tabular}{|c|c|c|c|}
\hline & $\begin{array}{c}\text { Control Group } \\
(\mathrm{n}=55)\end{array}$ & $\begin{array}{l}\text { Treated Group } \\
\quad(\mathrm{n}=54)\end{array}$ & $\begin{array}{c}\mathrm{P} \\
(\mathrm{CI} 95 \%)\end{array}$ \\
\hline $\begin{array}{l}\text { Duration of intubation } \\
\text { (hours/min), median * }\end{array}$ & $10 \mathrm{~h} 15 \mathrm{~min}$ & $10 \mathrm{~h} 55 \mathrm{~min}$ & $\begin{array}{c}0.831 \\
(0.24-1.78)\end{array}$ \\
\hline $\begin{array}{l}\text { ICU length (days), mean } \\
\text { (SD) }\end{array}$ & $5.9( \pm 10.2)$ & $4.1( \pm 6.9)$ & $\begin{array}{c}0.481 \\
(0.44-1.67)\end{array}$ \\
\hline Hypoglicemia $(\%)$ & 2.1 & 2.9 & $\begin{array}{c}0.67 \\
(0.84-1.43)\end{array}$ \\
\hline $\begin{array}{l}\text { Blood transfusion (units), } \\
\text { mean (SD) }\end{array}$ & $4( \pm 2.8)$ & $3.5( \pm 3.2)$ & $\begin{array}{c}0.202 \\
(0.65-1.34)\end{array}$ \\
\hline Infection rate $(\%)$ & 35.3 & 19.2 & $\begin{array}{c}0.119 \\
(0.23-2.2)\end{array}$ \\
\hline Postoperative fever (\%) & 11.1 & 0.0 & $\begin{array}{c}0.123 \\
(0.24-1.1)\end{array}$ \\
\hline Renal dysfunction (\%) & 9.8 & 6.4 & $\begin{array}{c}0.717 \\
(0.67-1.45)\end{array}$ \\
\hline $\begin{array}{l}\text { Neurological dysfunc- } \\
\text { tion }(\%)\end{array}$ & 9.8 & 2.1 & $\begin{array}{c}0.207 \\
(0.34-1.65)\end{array}$ \\
\hline $\begin{array}{l}\text { Hospital length (days), } \\
\text { mean (SD) }\end{array}$ & $17( \pm 16)$ & $12( \pm 7)$ & $\begin{array}{c}0.060 \\
(0.24-1.01)\end{array}$ \\
\hline Death $(\%)$ & 5.9 & 6.4 & $\begin{array}{c}1.0 \\
(0.24-1.2)\end{array}$ \\
\hline
\end{tabular}

$P \leq 0,05$ value statistically significant

* mean values are very variable: $37 \mathrm{~h} 11 \mathrm{~min}( \pm 80 \mathrm{~h} 7 \mathrm{~min})$ in control group and $31 \mathrm{~h} 50 \mathrm{~min}( \pm 141 \mathrm{~h} 58 \mathrm{~min})$ in treated group

the patients from the treated group, without any statistically significant difference (Table 6).

No differences between groups were found concerning neurological dysfunction. A neurologist blinded to the protocol examined all of the patients and detected neurological dysfunction in $9.8 \%$ of the patients in the control group and $2.1 \%$ in the treated group. The length of stay in the hospital was slightly different between the two groups, with the control group staying 17 days compared to 12 days for the treated group. However, this difference was not statistically significant. Finally, the survival rate was examined as the principal end-point at postoperative day 30 ,

Table 6 - Types of Infection

\begin{tabular}{lccc}
\hline & $\begin{array}{c}\text { Control Group } \\
(\mathrm{n}=55)\end{array}$ & $\begin{array}{c}\text { Treated Group } \\
(\mathrm{n}=54)\end{array}$ & $\begin{array}{c}\mathrm{P} \\
(\mathrm{CI} 95 \%)\end{array}$ \\
\hline $\begin{array}{l}\text { Respiratory tract } \\
\text { RT })\end{array}$ & $38.9 \%$ & $44.4 \%$ & 0.4 \\
$\begin{array}{l}\text { Infection of urinary } \\
\text { system (IUS) }\end{array}$ & $11.1 \%$ & $22.2 \%$ & $\begin{array}{c}0.45-1.31) \\
\text { Sepsis }\end{array}$ \\
$\begin{array}{llcc} \\
\text { Surgical Wound }\end{array}$ & $11.1 \%$ & $22.2 \%$ & $0.66-1.81)$ \\
& $16.7 \%$ & $11.1 \%$ & $0.64-1.76)$ \\
\hline
\end{tabular}

$\mathrm{P} \leq 0,05$ value statistically significant 
Table 7 - Rates of survival after 30 days of surgery.

\begin{tabular}{ccc}
\hline Control Group $(\mathrm{n}=55)$ & Treated Group $(\mathrm{n}=54)$ & $\mathrm{P}$ \\
\hline $52(94.5 \%)$ & $52(96.2 \%)$ & 0.31 \\
\hline $\mathrm{P} \leq 0,05$ value statistically significant &
\end{tabular}

and the results were not different between groups $(\mathrm{p}=0.71)$, as shown in Table 7.

\section{DISCUSSION}

The main results of our study demonstrate that there are no significant differences between our two groups, the intensively treated (glucose level of $80-130 \mathrm{mg} / \mathrm{dl}$ ) and the control (glucose level of 160-200 mg/dl). Specifically, we examined the duration of mechanical ventilation, the length of stay in the ICU and hospital, the incidence of postoperative infection, required units of blood for transfusions, incidence of renal dysfunction, presence of neurological dysfunction and number of deaths within 30 days after the operation.

Patients from both groups were comparable with regard to age, gender and height, but they differed in weight and body mass index. In addition, there were no differences between the control and treated groups for physical status (ASA), as well as Canadian and EuroSCORE® indices of risk. Diabetes mellitus and morbid obesity are considered risk factors in cardiac surgeries only in the score index proposed by Bernstein and Parsonnet; both groups were similar considering these co-morbidities.

The regular use of methylprednisolone, administered as a single dose after anesthetic induction, is justified by some studies to attenuate the inflammatory response to $\mathrm{CPB} .{ }^{3,30} \mathrm{It}$ is likely that methylprednisolone contributed to additional elevation of serum glucose levels in our patients. The examined groups did not show any differences concerning intraoperative variables, including duration of surgery, length of CPB and usage of antifibrinolytic.

The results of our study are different from those of other recent . These differences could be explained by the different populations examined and/or by the methodological design. ${ }^{18-20,22}$ The patients included in our series were scheduled for elective surgeries; therefore, emergency surgeries, patients with renal dysfunction and patients using inotropic support were excluded from this study. These same exclusion factors did not apply to patients in the studies by Van den Berghe et al. and Krinsley et al. ${ }^{15,18}$ These studies included surgical and clinical ICU patients, most of whom had post-operative complications or decompensate clinical diseases. Another possible reason for the lack of statistical significance in results from the two groups in the present study is the relatively limited duration of glucose control, since it was maintained only during surgery and for 36 hours in the ICU. Studies which demonstrated a benefit from strict control of the glucose level on outcomes included protocols with durations longer than 5 days. ${ }^{15,18,20}$

Hyperglycemia is common in intensive care unit patients, and the severity of hyperglycemia has been repeatedly associated with adverse outcomes of a variety of illnesses, including critical illnesses. Traditionally, insulin is not administered until blood glucose exceeds $180-200 \mathrm{mg} /$ $\mathrm{dl}$, based on the rationale that such mild increases are not deleterious, and tighter control might be complicated by life-threatening hypoglycemia. In 2001, a large, randomized, controlled study revealed that intensive insulin therapy to maintain normal blood glucose levels $(<110 \mathrm{mg} / \mathrm{dl})$ saved lives and prevented debilitating and expensive complications in a predominantly surgical ICU population..$^{18}$ This study was followed with a publication by Krinsley et al. ${ }^{19}$ who reported that when intensive insulin therapy is implemented in real-life intensive care situations, the benefits on morbidity and mortality are largely reproduced. The subsequent randomized, controlled study of intensive insulin therapy in a very ill medical ICU population, with a high co-morbidity and a high risk of death, confirmed the morbidity benefits and, when blood glucose control was continued for at least three days, reduced mortality. ${ }^{20}$ Hence, since the 2001 publication, which has been strongly supported by other more recent studies, many centers have initiated blood glucose control in their ICUs.

Recent reports question whether this protocol fits all patients and if consequent hypoglycemia, which is the risk of controlling blood glucose with insulin, could have a negative impact on patient outcomes. ${ }^{22-25}$ Blood glucose control with insulin has an associated risk of hypoglycemia. In both of the studies mentioned above, hypoglycemia occurred more frequently in patients who did not survive. However, as hypoglycemia was associated with mortality in both insulin therapy groups, it remained unclear whether this association was causal. Fears of hypoglycemia and its imagined consequences, based on deeply rooted emotional beliefs rather than evidence, explain why hypoglycemia is often considered more dangerous than hyperglycemia in the critically ill. Hypoglycemia is generally arbitrarily defined as blood glucose $<50 \mathrm{mg} / \mathrm{dl}$ with neuroglycopenic symptoms or $<40 \mathrm{mg} / \mathrm{dl}$ in the absence of symptoms. In the ICU, however, sedation may mask symptoms of neuroglycopenia, and counter-regulatory responses may be impaired, which complicates the diagnosis of hypoglycemia in this setting. Thus, the clinical relevance of a brief hypoglycemic episode, independent of illness severity, remains unclear. ${ }^{32,33}$ 
In our study, hypoglycemia occurred in $2.1 \%$ of the control group and in $2.9 \%$ of patients from the treated group, with no statistical difference between groups. There were no cases of neurological sequelae of hypoglycemia, which suggests that the protocol was safe in this population.

One important point that deserves discussion is the fact that 11 patients were lost to follow-up, which may have biased the results.

Vriesendorp et al..$^{34}$ assessed the effect of incidental hypoglycemia on outcomes of critically ill patients. The risk of hypoglycemia with this regimen was $6.9 \%$. They studied a total of 302 patients. Matching of cases and controls was performed for age, sex, severity of illness, and duration of ICU stay before the hypoglycemic event. They found no association between hypoglycemia and early (within five days of the event) or late (hospital) mortality. The data reported by Vriesendorp et al. suggest against using the risk of hypoglycemia as a reason to avoid intensive insulin therapy. The prospective, randomized, multicenter VISEP (volume substitution and insulin therapy in severe sepsis) trial was designed as a four-arm study to assess the choice of fluid resuscitation and the efficacy and safety of intensive insulin therapy in patients with severe sepsis and septic shock, using mortality and organ dysfunction as outcome variables. ${ }^{24}$ The insulin arm of this study was stopped prematurely because the rate of hypoglycemia in the intensive treatment group (12.1\%) was considered unacceptably high. In our study, we had a low rate of hypoglycemia that was similar between groups (2.9\% in treated group vs. $2.1 \%$ in control group, $p=0.67$ ), and these results can be explained in part by the acquired glucose levels $(126.69( \pm 10.82) \mathrm{mg} / \mathrm{dl}$ in the treated group and $168.21( \pm$ $28.29) \mathrm{mg} / \mathrm{dl}$ in the control group). Consequently, it is possible to assume that the use of this protocol may be safe in patients undergoing open-heart surgeries, although the glucose levels remain higher than classical recommendations, which could explain our results. This study, which applied less intensive glycemic control, had good outcomes and did not result in excess hypoglycemia. This data contrasts with those from a recent study ${ }^{35}$ which showed that strict intraoperative glycemic control (glucose levels between 80 and $100 \mathrm{mg} / \mathrm{dl}$ ) is associated with higher rates of death and stroke.

Several recent studies clearly identify the development of hyperglycemia as an important risk factor for mortality and morbidity of critically ill patients. In patients undergoing cardiac surgery, hyperglycemia has been associated with a substantial mortality risk and delayed extubation. ${ }^{36}$ Intraoperative hyperglycemia seemed to be an independent risk factor for adverse outcome after cardiac surgery. ${ }^{37-42}$ Furthermore, hyperglycemia was associated with an increased risk of death in patients with myocardial infarction and also in patients with risk of congestive heart failure and cardiogenic shock. ${ }^{38}$ From the predictive value of hyperglycemia for decreased survival of patients with a severe brain injury, a significant relationship was found between high blood glucose levels and impaired neurological status, weakened pupil reactivity, intracranial hypertension and a longer hospital stay. ${ }^{43,44}$ In addition, a strong link has been described between increased blood glucose levels and the risk of critical illness polyneuropathy in sepsis and the systemic inflammatory response syndrome. ${ }^{44}$ Results of multiple-center trials on tight blood glucose control in the critically ill and of studies on the most optimal level of blood glucose for different patient populations are still lacking. While we await those results, the current evidence, largely provided by the two Leuven trials and the implementation study by Krinsley, is in favor of controlling blood glucose levels in the ICU. Indeed, these studies showed that many lives were saved with this intervention, despite a higher prevalence of hypoglycemia. Hyperglycemia is deleterious for critically ill patients. Dr. Vriesendorp and colleagues $^{34}$ have now shown that incidental, brief episodes of hypoglycemia, when rapidly recognized and appropriately treated, are not likely to cause serious harm.

To safely target normoglycemia in ICU patients, intensivists and ICU nurses alike anxiously await accurate, continuous blood glucose sensors. This vital tool should be added to the bedside monitor, with appropriate alarms and trends to facilitate safe implementation of insulin therapy. Ideally, a closed-loop computerized system with an accurate continuous sensor and an insulin pump linked via an automated algorithm will conserve precious nursing time. ${ }^{44}$ Such devices are not yet available, and systems that are commercially available and perform relatively well for patients with diabetes do not work for critically ill patients. It is hoped that validated systems will become available soon and find their way to the ICU. In this study, we used a glucose meter that is widely available in ICUs world-wide.

Although this pilot study showed no difference in clinical outcomes among the two study groups, the sample size was not large enough to allow for any definite conclusions or recommendations on the effect of strict glucose control versus less intensive control. However, the sample size is sufficient to address the following important questions. Who are the patients that really benefit from strict glucose control? What is the safest protocol regarding hypoglycemic events? Do the patients improve with glucose control or solely because of the improved care included in the protocols? Our study showed that in a population of 109 patients undergoing cardiac surgery with cardiopulmonary bypass, both protocols are safe, can be easily achieved and do not differ regarding clinical outcomes. However, due to the small study sample, a clinically relevant effect in the population could not be excluded. 


\section{ACKNOWLEDGEMENTS}

We acknowledge the physicians and nurses from the surgical room and the ICU who helped collect data. We are indebted to Julia Fukuschima for her statistical analyses.

Financial support: E.J. Zerbini Foundation.

\section{REFERENCES}

1. Kernan WN, Viscoli CM, Inzucchi SE, Brass LM, Dawn M, Shulman GI. Prevalence of abnormal glucose tolerance following a transient ischemic attack or ischemic stroke. Arch Intern Med. 2005;165:227-3.

2. Dora B, Mihci E, Eser A, Ozclenir C, Caker M, Balaci MK. Prolonged hyperglycemia in the early subacute period after cerebral infarction: effects on short term prognosis. Acta Neurol Belg. 2004;104:64-7.

3. Alvarez-Sabin J, Molina CA, Ribo M, Arenillas JF, Montaner J, Huertas R. Impact of admission hyperglycemia on stroke outcome after thrombolysis: risk stratification in relation to time to reperfusion. Stroke. 2004;35:2493-8.

4. Williams LS, Rotich J, Qi R, Fineberg A, Espay A, Bruno S. Effects of admission hyperglycemia on mortality and costs in acute ischemic stroke. Neurology. 2002;59:67-7.

5. Capes SE, Hunt D, Malmberg K, Pathak P, Gerstein HC. Stress hyperglycemia and prognosis of stroke in nondiabetic and diabetic patients: a systematic overview. Stroke. 2001;32:2426-32.

6. Suleiman M, Hammerman H, Boulos M, Kapeliorrich MR, Suleiman A, Agmon Y. Fasting glucose is an important independent risk factor for 30-day mortality in patients with acute myocardial infarction: a prospective study. Circulation. 2005;111:754-60.

7. Kosuge M, Kimura K, Ishikawa T, Shimizi T, Hibi K, Toda N. Persistent hyperglycemia is associated with left ventricular dysfunction in patients with acute myocardial infarction. Circ J. 2005;69:23-8.

8. Choi KM, Lee KW, Kim SG, Kim NH, Park CG, Suo HS. Inflammation, insulin resistance, and glucose intolerance in acute myocardial infarction patients without a previous diagnosis of diabetes mellitus. J Clin Endocrinol Metab. 2005;90:175-80.

9. Timmer JR, van der Horst IC, Ottervanger JP, Henriques JPS, Hoortje JCA, Boer MJ. Prognostic value of admission glucose in non-diabetic patients with myocardial infarction. Am Heart J. 2004;148:399-404.

10. Trence DL, Kelly JL, Hirsch IB. The rationale and management of hyperglycemia for in-patients with cardiovascular disease: time for change. J Clin Endocrinol Metab. 2003;88:2430-7.

11. Laird AM, Miller PR, Kilgo PD, Meredith JW, Chang MC. Relationship of early hyperglycemia to mortality in trauma patients. J Trauma. 2004:56:1058-62.

12. Vriesendorp TM, Morelis OJ, Devries JH, DeVries JH, Legemate DA, Hokstra JBL. Early post-operative glucose levels are an independent risk factor for infection after peripheral vascular surgery: a retrospective study. Eur J Vasc Endovasc Surg. 2004;28:520-5.

13. Jeremitsky E, Omert LA, Dunham CM, Wilberger J, Rodriguez A. The impact of hyperglycemia on patients with severe brain injury. J Trauma 2005;58:47-50

14. Van den Berghe G. How does blood glucose control with insulin save lives in intensive care? J Clin Invest. 2004;114:1187-95.
15. Krinsley JS. Association between hyperglycemia and increased hospital mortality in a heterogeneous population of critically ill patients. Mayo Clin Proc. 2003;78:1471-8.

16. Furnary AP, Zerr KJ, Grunkemeier GL, Starr A. Continuous intravenous insulin infusion reduces the incidence of deep sternal wound infection in diabetic patients after cardiac surgical procedures. Ann Thorac Surg. 1999;67:352-60.

17. Furnary AP, Gao G, Grunkemeier GL, Grunkemeier GL, Wu YX, Zerr KJ. Continuous insulin infusion reduces mortality in patients with diabetes undergoing coronary artery bypass grafting. J Thorac Cardiovasc Surg. 2003;125:1007-21.

18. Van den Berghe G, Wouters P, Weekers F, Verwaest C, Bruyninckx F, Schetz M. Intensive insulin therapy in the critically ill patients. N Engl J Med. 2001;345:1359-67.

19. Krinsley JS. Effect of an intensive glucose management protocol on the mortality of critically ill adult patients. Mayo Clin Proc. 2004;79:9921000 .

20. Van den Berghe G, Wilmer A, Hermans G, Messerman W, Wouters PJ, Milants I. Intensive insulin therapy in medical intensive care patients. N Engl J Med. 2006;354:449-61.

21. Vanhorebeek, I, Langouche L, Van den Berghe G. Tight blood glucose control: What is the evidence? Critical Care Med. 2007;35(9) Suppl:S496-502.

22. Van den Berghe G, Wilmer A, Milants I, Wouters PJ, Bouckaert B, Bruyninckx F. Intensive insulin therapy in mixed medical/surgical ICU: benefit vs harm. Diabetes. 2006;55:3151-9.

23. Gandhi GY, Nuttall GA, Abel MD, Mullany CJ, Schaff HV, O’Brien $\mathrm{PC}$ et al. Intensive intraoperative insulin therapy versus conventional glucose management during cardiac surgery: a randomized trial. Ann Intern Med. 2007;146:233-43.

24. Brunkhorst FM, Engel C, Bloos F, Meier-Hellmann A, Ragaller M, Weiler N. Intensive Insulin Therapy and Pentastarch Resuscitation in Severe Sepsis. N Engl J Med. 2008;358:125-39.

25. Van den Berghe G. Does tight blood control glucose during cardiac surgery improve outcome? Ann Intern Med. 2007;146:307-8.

26. Zerr K, Furnary A, Grunkemeier G, Bookin S, Kanhere V, Starr A Glucose control lowers the risk of wound infection in diabetic after open heart operations. Ann Thorac Surg. 1997;63:356-61.

27. Nashef S, Roques F, Michel P, Gauducheau E, Lemeshow S, Salamon R: European system for cardiac operative risk evaluation (EuroSCORE®). Eur J Cardio Thoracic Surg. 1999;16:9-13.

28. Tu J, Jaglal S, Naylor C. Interventional cardiology/cardiac surgery: multicenter validation of a risk index for mortality, intensive care unit stay, and overall hospital length of stay after cardiac surgery. Circulation. 1995;91:677-84. 
29. Bernstein A, and Parsonnet V. Bedside estimation of risk as an aid for decision-making cardiac surgery. Ann Thorac Surg. 2000;69:823-8.

30. Maharaj C, Laffey JG. New strategies to control the inflammatory response in cardiac surgery. Cur Op Anaesth. 2004;17:35-48.

31. Farstad M, Heltne JK, Rynning SE, Onarheim H, Mongstad A, Eliassen F. Can the use of methylprednisolone, vitamin C, or $\alpha$-trinisitol prevent cold-induced fluid extravasation during cardiopulmonary bypass in piglets. J Thorac Cardiovasc Surg. 2004;127:525-34.

32. Boyle PJ, Schwartz NS, Shah SD, Clutter WE, Guyer PE. Plasma glucose concentration at the onset of hypoglycemic symptoms in patients with poorly controlled diabetes and in non-diabetics. N Engl J Med. 1988;318:1487-92.

33. Merimee TJ, Tyson JE. Stabilization of plasma glucose during fasting: Normal variation in two separate studies. N Engl J Med. 1974;291:12758.

34. Vriesendorp TM, DeVries JH, van Santen S, Moeneralan HS, deJonge E, Ross YB. Evaluation of short-term consequences of hypoglycemia in an intensive care unit. Crit Care Med. 2006;34:2714-8.

35. Muhlestein JB, Anderson JL, Horne BD, Lavasani F, Allen Maycock CA, Bair TL, Pearson RR, Carlquist JF; Intermountain Heart Collaborative Study Group. Effect of fasting glucose levels on mortality rate in patients with and without diabetes mellitus and coronary artery disease undergoing percutaneous coronary intervention. Am Heart J. 2003;146:351-8.

36. Gandhi GY, Nuttall GA, Abel MD, Mullany CJ, Schaff HV, Williams BA, Schrader LM, Rizza RA, McMahon MM. Intraoperative hyperglycemia and perioperative outcomes in cardiac surgery patients. Mayo Clin Proc. 2005;80:862-6.
37. Capes SE, Hunt D, Malmberg K, Gerstein HC. Stress hyperglycaemia and increased risk of death after myocardial infarction in patients with and without diabetes: a systematic overview. Lancet. 2000;355:773-8.

38. Yendamuri S, Fulda GJ, Tinkoff GH. Admission hyperglycemia as a prognostic indicator in trauma. J Trauma. 2003;55:33-8.

39. Laird AM, Miller PR, Kilgo PD, Meredith JW Chang MC. Relationship of early hyperglycemia to mortality in trauma patients. J Trauma. 2004;56:1058-62.

40. Bochicchio GV, Sung J, Joshi M, Bochicchio K, Johnson SB, Meyer $\mathrm{W}$, Scalea TM. Persistent hyperglycemia is predictive of outcome in critically ill trauma patients. J Trauma. 2005;58:921-4.

41. Sung J, Bochicchio GV, Joshi M, Bochicchio K, Tracy K, Scalea TM. Admission hyperglycemia is predictive of outcome in critically ill trauma patients. J Trauma 2005;59:80-3.

42. Rovlias A, Kotsou S. The influence of hyperglycemia on neurological outcome in patients with severe head injury. Neurosurgery. 2000;46:33542.

43. Jeremitsky E, Omert LA, Dunham M, Wilberger J, Rodriguez A. The impact of hyperglycemia on patients with severe brain injury. J Trauma. 2005;58:47-50.

44. Soo Hoo GW. Tight blood glucose control in the ICU: how best to measure glucose control? Chest. 2008;133:316-7. 